\title{
Antenatal Depression and Anxiety Among Women with Threatened Abortion: A Case-Control Study
}

\section{Bahar SARIIBRAHIM ASTEPE${ }^{1}$, Sukriye BOSGELMEZ ${ }^{2}$}

Kocaeli, Turkey

OBJECTIVE: Threatened abortion is a stressful condition for a pregnant woman which may influence mental health. This study aims to investigate the relationship between threatened abortion, anxiety, and depression during pregnancy.

STUDY DESIGN: Study group consisted of 121 pregnant women $<20$ weeks of gestation having vaginal bleeding; control group consisted of 129 pregnant women $<20$ weeks of gestation not having vaginal bleeding in their pregnancy until that time. Hospital anxiety and depression scale was used to assess potential anxiety and depression.

RESULTS: Statistical analyses indicated that (i) vaginal bleeding group had significantly higher rates of moderate/ severe anxiety ( $28.1 \%$ vs. $14.7 \% p=0.010)$; (ii) there was no statistically significant difference between depression rates of the women according to the presence of vaginal bleeding $(38.8 \%$ vs. $34.9 \%$ $p=0.517$ ); (iii) low education (OR=2.233; $95 \% \mathrm{Cl}: 1.177-4.236 ; p=0.014$ ) was possible predictors of antenatal depression. Although in the univariate analyses age, gravidity, and parity were associated with anxiety, only nulliparity was found as possible predictors of anxiety $(\mathrm{OR}=2.589 ; 95 \% \mathrm{Cl}: 1.362-4.922$, $p=0.004)$.

CONCLUSION: Pregnant women without obstetric complications had similar rates of depression and anxiety as in women with threatened abortion, although anxiety levels were higher in women with threatened abortion.

Keywords: Antenatal anxiety, Antenatal depression, Hospital anxiety and depression scale, Threatened abortion

Gynecol Obstet Reprod Med 2020;26(2):75-82

\section{Introduction}

Depression and anxiety are common all over the world. Depression is a major mental health problem that decreases the quality of life and leads to disability by affecting the functioning, creativity, and happiness of the person (1). International studies indicate that the vast majority of depression is seen in women between the ages of 18 and 44 , includ-

\footnotetext{
1 Department of Obstetrics and Gynecology, Health Science University Kocaeli Derince Training and Research Hospital, Kocaeli,

2 Department of Psychiatry, Health Science University Kocaeli Derince Training and Research Hospital, Kocaeli, Turkey

Address of Correspondence: $\quad$ Sukriye Bosgelmez

Kocaeli Derince Training and Research

Hospital Department of Psychiatry 41900

Derince Kocaeli, Turkey

bsukriye@hotmail.com

Submitted for Publication

12.12.2019

Accepted for Publication:

20.05.2019

ORCID IDs of the authors:

BSA: 0000-0002-9012-4802, SB:0000-0003-0529-9067
}

\begin{tabular}{|c|c|}
\hline $\begin{array}{c}\text { Quick Response Code: } \\
\text { angs. }\end{array}$ & Access this article online \\
\cline { 2 - 2 } & $\begin{array}{l}\text { Website: www.gorm.com.tr } \\
\text { e- mail: info@gorm.com.tr }\end{array}$ \\
\cline { 2 - 3 } & DOI:10.21613/GORM.2019.867 \\
\hline
\end{tabular}

How to cite this article: Sariibrahim Astepe B. and Bosgelmez S. Antenatal Depression and anxiety among women with Threatened Abortion: A CaseControl Study. Gynecol Obstet Reprod Med 2020;26(2):75-82 ing fertility processes such as pregnancy, childbirth, and puerperium (2). For women, pregnancy may be a source of happiness; however, stress, anxiety, anxious expectation, overloading of the negative mental emotions can also be seen sometimes (3). Pregnancy, delivery, at the end having a child bring many physiological and psychosocial changes, both mothers and fathers are required to face several new challenges during this period in their lives (4). The estimated prevalence of perinatal anxiety and depression vary between researches. A recent meta-analysis reported that the prevalence of antenatal depression was $25.8 \%$ in low- and middle-income countries (5). Perinatal anxiety is reported $18-20 \%$; most of pregnant women have both anxiety and depression $(6,7)$.

Obstetric complications may be associated with antenatal depression and anxiety (4). Threatened abortion is a common complication, especially in the first trimester, which affects $14-21 \%$ of all pregnancies (8). It is reported that $50 \%$ of pregnancies with vaginal bleeding continue (9). Unpredictable continuity of pregnancy may increase the psychological burden of expecting mothers

It was indicated that previous miscarriage may be a risk factor for antenatal depression and anxiety $(10,11)$. However, the relationship between threatened abortion, anxiety, and depression during pregnancy has not been studied thoroughly. 
One study from Singapore reported that depression and anxiety were higher in women facing threatened miscarriage, and threatened miscarriage may be a risk factor for antenatal depression (12). Mental health symptoms of these women may remain unnoticed. Therefore, we examine how threatened abortion is associated with anxiety and depression in a group of pregnant women.

\section{Material and Method}

\section{Subjects}

This case-control study was conducted with 250 pregnant women evaluated at Health Science University Kocaeli Derince Training and Research Hospital Obstetrics and Gynecology Clinics between January 2015 and January 2016. The research was carried out with pregnant women under 20 weeks of gestation aged 18-44 years. Pregnant women with detected systemic illness such as diabetes mellitus, hypertension, cardiac disease or pulmonary disease were not included in the study. Study group consisted of 121 pregnant women under 20 weeks of gestation, positive fetal heart beat detected by ultrasonographically and those having vaginal bleeding. Thirty-two pregnant women in the study group hospitalized for threatened abortion until vaginal bleeding ceased. Control group consisted of 129 healthy pregnant women who admitted obstetrics and gynecology outpatient clinics for their routine antenatal check-ups, under 20 weeks of gestation, positive fetal heart beat detected by ultrasonographically and those not having vaginal bleeding in their pregnancy until that time. The patient information sheet was given and patients who wanted to participate were given self-report questionnaire form. All participants were competent to Turkish language, therefore all questionnaires and interviews were performed in Turkish. Seven patients ( 5 patients with vaginal bleeding and 2 patients without vaginal bleeding) had psychiatric treatment history. Two patients had been already treated for depression using SSRI (selective serotonin reuptake inhibitors). Four patients were treated for anxiety disorders previously, one was already in SSRI treatment for anxiety disorder. Since the study aims to determine the association between threatened abortion and current-incidental anxiety/depression. Patients with past psychiatric history and already in treatment were excluded. Psychiatric consultation was offered to patients who met depression or anxiety caseness.

Ethical approval was provided by Kocaeli University Ethical Committee with the number KOU KAEK 2014/357 at November 2014. Written informed consents for using data were obtained from the patients and the study was conducted in accordance with the Declaration of Helsinki.

\section{Material and Method}

The questionnaire form includes Hospital Anxiety and Depression Scale (HADS) and sociodemographic data sheet. Questionnaire related to sociodemographic data includes edu- cational status, occupational status, income, housing, number of person living at home, and smoking, medical history, obstetric history including gravity, parity, abortion, vaginal birth, and caesarian section. Educational status was categorized as 8 years and less (elementary and secondary school) and higher than 8 years (high school and university). All patients were married.

Hospital anxiety and depression scale which is a self-report questionnaire was developed to identify caseness of anxiety disorders and depression. Caseness is the term which refers to possible or probable anxiety disorders and depression. It contains 14 items with four possible answer choices to each item. Each item is scored from 0 (not present) to 3 (considerable). It contains seven items for anxiety and seven items for depression. The HADS has been validated as a convenient tool for uncovering anxiety and depression cases in antenatal and gynecology patients (13). The cut-off score of 8 was considered optimal to identify potential anxiety and depression (14). The cut-off score $\geq 8$ for either HADS anxiety or depression subscales determined caseness of the anxiety or depression (15). Scores $\geq 11$ indicate moderate; $\geq 16$ indicate severe symptoms. The cut-off score $\geq 8$ for anxiety has a specificity of 0.78 and a sensitivity of 0.9 ; for depression has a specificity of 0.79 and a sensitivity of 0.83 (15). The HADS has good psychometric properties as a psychological screening tool for identifying general hospital patients requiring further psychiatric evaluation; it is not used to make diagnoses of psychiatric disorders (16).

Somatic symptoms like fatigue, dizziness, and sleep disturbances are common during pregnancy $(17,18)$. These symptoms may be misinterpreted as psychological distress. HADS is especially suitable to investigate psychological distress in pregnancy as it does not have questions on somatic symptoms (17). Its psychometric properties in the antenatal population are highly valuable, since the sensitivity for anxiety subscale is $92.9 \%$, specificity is $86.5 \%$; the sensitivity for depression subscale is $92.1 \%$, specificity is $91.1 \%$ (13). Reliability and validity of Turkish version of HADS was studied by Aydemir et al. (1993) (19).

\section{Statistics}

Statistical parameters were computed using the SPSS 17.0 software. In addition to descriptive statistics (mean, standard deviation, median, frequency, and ratio, minimum, maximum) Student $t$ test was used in evaluation of quantitative data and Mann Whitney U test was used in comparison of non-normal distribution data. Pearson's Chi-square test and Yates' Continuity Correction test (Chi-square test with Yates' correction) were used for comparison of qualitative data. In the second step, to determine possible predictors of anxiety and depression, logistic regression analyses were performed using those variables that showed significance in the literature. The statistical significance was defined as $p<0.05$. 


\section{Results}

There were a total of 250 patients under 20 weeks of gestation admitted to Obstetrics and gynecology outpatient clinic between January 2015 and January 2016. These patients agreed to participate in the study and fill out the questionnaire form. Of these patients, 121 had vaginal bleeding, 129 had no vaginal bleeding.

When the demographical and descriptive characteristics of the patients were examined; employed and women having 2 abortion and over were found to have higher incidence of vaginal bleeding ( $p=0.030$ and $p=0.005$ respectively; table 1 ). The gestation week and parity of patients with vaginal bleeding was lower than those without vaginal bleeding (both $p<$ 0.001 , table I)

In the whole study group $14.8 \%$ of women $(n=37)$ had only depression; $21.2 \%(n=53)$ had both anxiety and depres- sion; $26.4 \%(\mathrm{n}=66)$ had only anxiety. In vaginal bleeding group, $53 \%(n=64)$ of women met anxiety caseness (score of $\geq 8)$; in control group, $43 \%(n=55)$ of women met anxiety caseness (score of $\geq 8$ ). There was no statistically significant difference between these ratios. However, the mean anxiety scores of women with vaginal bleeding were significantly higher than those without vaginal bleeding ( $p=0.025$, table II). When moderate/severe anxiety levels (score of $\geq 11$ ) were taken into consideration, vaginal bleeding group had significantly higher anxiety ( $28.1 \%$ vs. $14.7 \% p=0.010)$. Depression caseness (score of $\geq 8$ ) was $38.8 \%(n=47)$ in the vaginal bleeding group; $34.9 \%(n=45)$ in the control group. There was no statistically significant difference between the mean depression scores or depression caseness of the women including moderate/severe depression levels according to the presence of vaginal bleeding ( $p=0.796, p=0.517$, and $p=0.820$ respectively, table II).

Table I: Sociodemographical data and pregnancy characteristics of patients with vaginal bleeding and control group

\begin{tabular}{|c|c|c|c|}
\hline & $\begin{array}{l}\text { Vaginal bleeding }(-) \\
(n=129) \\
n(\%) \text { or Mean }(S D)\end{array}$ & $\begin{array}{l}\text { Vaginal bleeding }(+) \\
(n=121) \\
n(\%) \text { or Mean }(S D)\end{array}$ & $p$ \\
\hline Age (years) & $27.24(4.88)$ & $28.94(6.24)$ & ${ }^{a} 0.230$ \\
\hline Educational attainment $\leq 8$ years & $83(64.3)$ & $67(55.4)$ & ${ }^{b} 0.148$ \\
\hline Working & $13(10.1)$ & $24(19.8)$ & ${ }^{b} 0.030^{\star}$ \\
\hline High Income & $15(11.6)$ & $28(23.1)$ & ${ }^{b} 0.054$ \\
\hline Housing (Rented) & $69(53.5)$ & $55(45.5)$ & ${ }^{b} 0.204$ \\
\hline Number of people at home $(\geq 4)$ & $53(41.1)$ & $45(37.2)$ & ${ }^{b} 0.062$ \\
\hline Smoking 15 (11.6) & $15(12.4)$ & c0.852 & \\
\hline Gestational week & $15.23(3.14)$ & $9.71(3.46)$ & ${ }^{a} 0.001^{* *}$ \\
\hline \multicolumn{4}{|l|}{ Gravidity } \\
\hline 1 & $40(31.0)$ & $40(33.0)$ & \\
\hline 2 & $47(36.4)$ & $36(29.8)$ & ${ }^{b} 0.520$ \\
\hline$\geq 3$ & $42(32.6)$ & $45(37.2)$ & \\
\hline \multicolumn{4}{|l|}{ Parity $^{1}$} \\
\hline 0 & $44(34.1)$ & $83(68.6)$ & \\
\hline 1 & $49(38.0)$ & $19(15.7)$ & ${ }^{a} 0.001^{* *}$ \\
\hline$\geq 2$ & $36(27.9)$ & $19(15.7)$ & \\
\hline \multicolumn{4}{|l|}{ Number of abortus ${ }^{2}$} \\
\hline 0 & $110(85.3)$ & $85(70.2)$ & \\
\hline 1 & $16(12.4)$ & $23(19.0)$ & ${ }^{b} 0.005^{\star *}$ \\
\hline$\geq 2$ & $3(2.3)$ & $13(10.7)$ & \\
\hline \multicolumn{4}{|l|}{ Caesarean section } \\
\hline 0 & $93(72.1)$ & $95(78.5)$ & \\
\hline 1 & $28(21.7)$ & $22(18.2)$ & ${ }^{b} 0.402$ \\
\hline$\geq 2$ & $8(6.2)$ & $4(3.3)$ & \\
\hline \multicolumn{4}{|l|}{ Number of vaginal birth } \\
\hline 0 & $76(58.9)$ & $77(63.7)$ & \\
\hline 1 & $26(20.2)$ & $20(16.5)$ & ${ }^{b} 0.701$ \\
\hline$\geq 2$ & $27(20.9)$ & $24(19.8)$ & \\
\hline Hemoglobin level & $12.03(1.10)$ & $12.08(1.13)$ & ${ }^{a} 0.721$ \\
\hline Medical illness & $21(16.3)$ & $17(14.0)$ & ${ }^{c} 0.820$ \\
\hline
\end{tabular}

a: Student $t$ test, ${ }^{b}:$ Pearson chi- square test, ${ }^{c}:$ Yates' continuity correction test. ${ }^{* *} p<0.01{ }^{*} p<0.05$

1: Nulliparity rates were higher in vaginal bleeding group. 2: Number of abortion was higher in vaginal bleeding group. 
Table II: Evaluation of anxiety and depression levels according to vaginal bleeding state

\begin{tabular}{|c|c|c|c|c|}
\hline & HADS scores & $\begin{array}{l}\text { Vaginal bleeding(-) } \\
(n=129)\end{array}$ & $\begin{array}{l}\text { Vaginal bleeding }(+) \\
(n=121)\end{array}$ & $p$ \\
\hline \multicolumn{5}{|c|}{ Anxiety score } \\
\hline Mean (SD) & & $7.07(3.65)$ & $8.15(3.90)$ & $0.025^{\star}$ \\
\hline \multicolumn{5}{|c|}{ Anxiety n (\%) } \\
\hline & High ( $\geq 8)$ & $55(42.6)$ & $64(52.9)$ & 0.105 \\
\hline & Normal $(<8)$ & $74(57.4)$ & $57(47.1)$ & \\
\hline & Mild/normal $(<11)$ & $110(85.3)$ & $87(71.9)$ & $0.010^{* *}$ \\
\hline & Moderate/severe $(\geq 11)$ & $19(14.7)$ & $34(28.1)$ & \\
\hline \multicolumn{5}{|c|}{ Depression score } \\
\hline Mean $(S D)$ & & $6.80(3.44)$ & $6.92(3.80)$ & 0.796 \\
\hline \multicolumn{5}{|c|}{ Depression n (\%) } \\
\hline & High ( $\geq 8)$ & $45(34.9)$ & $47(38.8)$ & 0.517 \\
\hline & Normal $(<8)$ & $84(65.1)$ & $74(61.2)$ & \\
\hline & Mild/normal $(<11)$ & $108(83.7)$ & $100(82.6)$ & 0.820 \\
\hline & Moderate/severe $(\geq 11)$ & $21(16.3)$ & $21(17.4)$ & \\
\hline
\end{tabular}

${ }^{*} t$ Test, HADS: Hospital anxiety and depression scale, ${ }^{* *}$ : Pearson chi- square test

There was no statistically significant difference between hemoglobin measurements according to anxiety and depression levels in all cases $(p>0.05)$.

When the sociodemographic characteristics of the patients were compared according to depression level, it was found that patients with depression scores $\geq 8$ have significantly lower education level and income than patients with depression scores $<8$ ( $p=0.001$ and $p=0.009$, respectively, table III).

Table III: Evaluation of sociodemographic data according to depression and anxiety levels in HADS

\begin{tabular}{|c|c|c|c|c|c|c|c|}
\hline & & \multicolumn{3}{|c|}{ Depression } & \multicolumn{2}{|c|}{ Anxiety } & \multirow[b]{3}{*}{$p$} \\
\hline & & $\begin{array}{l}\operatorname{High}(\geq 8) \\
(n=92)\end{array}$ & $\begin{array}{l}\text { Normal }(<8) \\
(n=158)\end{array}$ & & $\begin{array}{l}\operatorname{High}(\geq 8) \\
(n=119)\end{array}$ & $\begin{array}{l}\text { Normal }(<8) \\
(n=131)\end{array}$ & \\
\hline & & \multicolumn{2}{|c|}{$n(\%)$ or Mean (SD) } & $p$ & \multicolumn{2}{|c|}{$n(\%)$ or Mean (SD) } & \\
\hline Age (years) & & $27.05(5.29)$ & $28.0(5.79)$ & ${ }^{\mathrm{a}} 0.197$ & $26.87(5.69)$ & $28.37(5.41)$ & ${ }^{a} 0.034^{*}$ \\
\hline $\begin{array}{l}\text { Educational } \\
\text { attainment }\end{array}$ & $\leq 8$ years & $67(72.8)$ & $83(52.5)$ & ${ }^{b} 0.002^{\star *}$ & $70(58.8)$ & $80(61.1)$ & ${ }^{b} 0.717$ \\
\hline Employment & Not working & $83(90.2)$ & $130(82.3)$ & ${ }^{c} 0.088$ & $18(15.1)$ & $19(14.4)$ & ${ }^{c} 0.890$ \\
\hline Income & Low & $39(42.4)$ & $38(23.4)$ & ${ }^{b} 0.009^{* *}$ & $44(37.0)$ & $33(25.0)$ & ${ }^{b} 0.091$ \\
\hline Housing & Rented & $47(51.1)$ & $77(48.7)$ & ${ }^{b} 0.720$ & $62(52)$ & $62(47)$ & ${ }^{b} 0.451$ \\
\hline Number of people & $40(43.5)$ & $58(36.7)$ & ${ }^{b} 0.111$ & $46(38.7)$ & $52(39.7)$ & ${ }^{b} 0.190$ & \\
\hline at home $\geq 4$ & Smoking & $9(9.8)$ & $21(13.3)$ & ${ }^{c} 0.410$ & $16(13.4)$ & $14(10.6)$ & ${ }^{c} 0.503$ \\
\hline Gestational week & & $11.95(4.17)$ & $12.93(4.27)$ & ${ }^{a} 0.081$ & $12.45(4.32)$ & $12.66(4.19)$ & ${ }^{a} 0.425$ \\
\hline \multirow[t]{3}{*}{ Gravidity } & 1 & $26(28.2)$ & $54(34.2)$ & ${ }^{b} 0.625$ & $46(38.7)$ & $34(26.0)$ & ${ }^{b} 0.040^{*}$ \\
\hline & 2 & $32(34.8)$ & $51(32.3)$ & & $40(33.6)$ & $43(32.8)$ & \\
\hline & $\geq 3$ & $34(37.0)$ & $53(33.5)$ & & $33(27.7)$ & $54(41.2)$ & \\
\hline \multirow[t]{3}{*}{ Parity } & 0 & $48(52.2)$ & $79(50.0)$ & ${ }^{b} 0.571$ & $71(59.7)$ & $56(42.7)$ & ${ }^{b} 0.028^{*}$ \\
\hline & 1 & $27(29.3)$ & 41 (25.9) & & $26(21.8)$ & $42(32.1)$ & \\
\hline & $\geq 2$ & $17(18.5)$ & $38(24.1)$ & & $22(18.5)$ & $33(25.2)$ & \\
\hline \multirow[t]{3}{*}{ Number of abortion } & 0 & $71(77.2)$ & $124(78.5)$ & ${ }^{b} 0.199$ & $93(78.4)$ & $102(78)$ & ${ }^{b} 0.965$ \\
\hline & 1 & $12(13.0)$ & $27(17.1)$ & & $18(15.2)$ & $21(15.9)$ & \\
\hline & $\geq 2$ & $9(9.8)$ & $7(4.4)$ & & $8(6.4)$ & $8(6.1)$ & \\
\hline Number of & 0 & $69(75.0)$ & $119(75.3)$ & ${ }^{b} 0.625$ & $95(80.0)$ & $93(71.2)$ & ${ }^{b} 0.264$ \\
\hline \multirow[t]{2}{*}{ caesarean section } & 1 & $20(21.7)$ & $30(19.0)$ & & $19(16.0)$ & $31(23.5)$ & \\
\hline & $\geq 2$ & $3(3.3)$ & $9(5.7)$ & & $5(4.0)$ & $7(5.3)$ & \\
\hline \multirow[t]{3}{*}{ Number of vaginal birth } & 0 & $52(56.5)$ & $101(63.9)$ & ${ }^{b} 0.354$ & $81(68.1)$ & $72(54.5)$ & ${ }^{b} 0.105$ \\
\hline & 1 & $21(22.8)$ & $25(15.8)$ & & $18(15.1)$ & $29.8(22.0)$ & \\
\hline & $\geq 2$ & $19(20.7)$ & $32(20.3)$ & & $20(16.8)$ & $31(23.7)$ & \\
\hline Medical illness & & $11(12.0)$ & $27(17.1)$ & ${ }^{c} 0.276$ & $15(12.6)$ & $23(17.6)$ & ${ }^{c} 0.276$ \\
\hline
\end{tabular}

HADS: Hospital anxiety and depression scale, a: Student t test, ${ }^{b}:$ Pearson chi- square test, ${ }^{c}$ :Yates' continuity correction test ${ }^{* *} p<0.01{ }^{*} p<0.05$ 
When patients with high $(\geq 8)$ anxiety scores were compared with patients with low $(<8)$ anxiety scores, it was found that age, gravidity, and parity were significant factors ( $p=$ $0.034 ; p=0.040 ; p=0.028$, respectively; table 3 ). The age of those with high anxiety scores were found to be lower than those with normal scores $(p=0.034)$. Patients with first pregnancy $(\mathrm{G} 1)$, not having birth before (P0) met anxiety caseness (score of $\geq 8$ ) more than other pregnant women ( $p=0.040 ; p=$ 0.028 , respectively, table 3 ).

Other variables like housing, number of people at home, and smoking status were not statistically significant (Table 3).

To determine possible predictors of depression caseness, logistic regression analysis (enter method) was performed. Depression caseness was entered as dependent variable; vaginal bleeding, age, education, income, housing, employment, smoking status, parity, history of abortion were independent variables. It was found that education level $\leq 8$ years $(\mathrm{OR}=$ 2.233; 95\% CI: $1.177-4.236 ; p=0.014$ was possible predictors of antenatal depression (Table IV).

To determine possible predictors of anxiety caseness, logistic regression analysis (enter method) was performed. Anxiety caseness was entered as dependent variable; vaginal bleeding, age, education, income, housing, employment, smoking status, parity, and history of abortion were independent variables. Nulliparity was found possible predictor of anxiety caseness $(\mathrm{OR}=2.589 ; 95 \% \mathrm{CI}: 1.362-4.922, p=0.004)$ (Table IV).

In the first regression analyses, vaginal bleeding was not associated neither depression nor anxiety. Further regression analysis was performed whether high level of depression or anxiety was possible predictor of vaginal bleeding. Vaginal bleeding was entered as dependent variable; age, education, income, housing, employment, smoking status, parity, history of abortion, depression, and anxiety were independent variables. Age (OR=1.092; 95\% CI: 1.027-1.162, $p=0.005)$; nulliparity $(\mathrm{OR}=9.548 ; \% 95 \mathrm{CI}: 3.742-24.329, p \leq 0.001)$; history of abortion $(\mathrm{OR}=0.277,95 \% \mathrm{CI}: 0.133-0.576, p=0.001)$ were found possible predictor of vaginal bleeding (Table IV).

\section{Discussion}

This study intended to examine the relationship between threatened abortion, anxiety, and depression in pregnancy compared with pregnancy without obstetric complication.

Our study shows that depression is common in pregnancy. Pregnant women without obstetric complication had similar rates of depression as in women with threatened abortion. There was no significant difference in depression prevalence of the pregnant women according to the presence of vaginal bleeding. A recent meta-analysis, which evaluated antenatal depression in low and middle-income countries, found the pooled prevalence estimate of antepartum depression was $25.3 \%$ (5). Antenatal depression rates vary $10.9-27.5 \%$ in Turkey depending on the instruments used to measure antenatal depression $(20,21)$. In a cross-sectional study, the prevalence of antenatal depression in patients with threatened preterm labor was $24.3 \%$ (22). This study found $14.8 \%$ of pregnant women had only depression; $21.2 \%$ had both anxiety and depression. Depression prevalence of this study correspond with these results.

In the present study, it was found that patients with low education were more likely to have depression. In the definitive analyses, patients with low income also had higher depression rate. However, this factor lost its significance in advanced analysis. Low education and low income were also identified as risk factors for antenatal depression in other studies $(21,23$, $24)$. Women with low education may not have adequate knowledge about pregnancy complication, have difficulties of coping and these may lead to uncertainty, anxiety, and depression (25).

The findings of the impact of age on antenatal depression are inconsistent. Some studies found older age was positively associated with antenatal depression $(6,20,21,23)$. Bödecs et al. and Quiao et al. reported that younger age is a risk factor

Table IV: Logistic regression analysis for depression and anxiety caseness and vaginal bleeding

\begin{tabular}{|c|c|c|c|c|c|c|}
\hline \multirow[t]{2}{*}{ Risk factors } & \multicolumn{2}{|l|}{ Depression } & \multicolumn{2}{|l|}{ Anxiety } & \multicolumn{2}{|l|}{ Vaginal bleeding } \\
\hline & Odds Ratio $(95 \% \mathrm{Cl})$ & $p$ & Odds Ratio $(95 \% \mathrm{Cl})$ & $p$ & Odds Ratio $(95 \% \mathrm{Cl})$ & $p$ \\
\hline Vaginal bleeding & $0.682(0.386-1.205)$ & 0.188 & $0.652(0.378-1.126)$ & 0.125 & & \\
\hline Age & $0.973(0.912-1.039)$ & 0.414 & $0.990(0.934-1.049)$ & 0.727 & $1.092(1.027-1.162)$ & 0.005 \\
\hline Low education level & $2.233(1.177-4.236)$ & 0.014 & $1.104(0.603-2.221)$ & 0.748 & $0.908(0488-1.687)$ & 0.759 \\
\hline Low income & $2.185(0.838-5.684)$ & 0.110 & $2.197(0.963-5.010)$ & 0.061 & $0.532(0.235-1.205)$ & 0.130 \\
\hline Housing (rented) & $0.964(0.535-1.735)$ & 0.902 & $1.119(0.649-1.895)$ & 0.705 & $0.651(0.378-1.121)$ & 0.121 \\
\hline Not working & $1.324(0.530-3.3089$ & 0.548 & $0.786(0.339-1.823)$ & 0.574 & $0.641(0.276-1.490)$ & 0.301 \\
\hline Smoking & $0.561(0.224-1.405)$ & 0.217 & $0.770(0.341-1.741)$ & 0.530 & $0.927(0.410-2.097)$ & 0.856 \\
\hline Parity $=0$ & $1.321(0.344-5.071)$ & 0.685 & $2.589(1.362-4.922)$ & 0.004 & $9.548(3.742-24.329)$ & $\leq 0.001$ \\
\hline Parity $=1$ & & & $1.031(0.488-2.177)$ & 0.937 & $1.321(0.531-3.285)$ & 0.550 \\
\hline History of abortion & $1.461(0.381-5.6)$ & 0.580 & $1.392(0.629-3.083)$ & 0.414 & $0.277(0.133-0.576)$ & 0.001 \\
\hline Depression & & & & & $0.717(0.404-1.271)$ & 0.254 \\
\hline Anxiety & & & & & $0.683(0.393-1.189$ & 0.178 \\
\hline
\end{tabular}


for antenatal depression $(24,25)$. Unemployment and being housewife are risk factors for antenatal depression $(21,24,26)$. However, in the present study, there was no association of depression with age or employment status.

It is reported that the experience of abdominal pain and/or vaginal bleeding in early pregnancy is highly anxiogenic (27). However, in the present study, the prevalence of anxiety was not different between women affected by threatened abortion and women not affected. Especially diagnostic uncertainty determines anxiety levels more than the positive or negative implications of diagnostic results (27). Women with threatened abortion in this study had higher rates of moderate/severe anxiety levels and higher total anxiety scores. These results may imply that threatened abortion does not create anxiety per se, but contributes to higher anxiety levels in pregnancy.

Younger age was associated with anxiety in pregnancy in different studies $(25,28)$. For younger women, adapting their new role and new expectations may be burdensome and they are more prone to exhibit anxiety and depressive symptoms in early pregnancy (18). Although anxiety caseness was higher in younger patients, it was not a risk factor in our finding.

Some studies showed that previous pregnancy loss was associated with higher anxiety and depression during pregnancy $(6,10,11,29)$. However, in our study population, previous pregnancy loss was not higher in patients with anxiety or depression supporting the studies of Bicking-Kinsey et al., Fisher et al. and Qiao et al. $(30,31,25)$.

Shapiro et al. found that prior live term birth was associated with lower pregnancy anxiety in all three trimesters (29). Ali et al., reported nulliparous or primiparous women as more at risk than multiparous women for anxiety (6). Present study showed that primigravid/nulliparous women had higher rates of anxiety. In advanced analysis, nulliparity was found as a risk factor for anxiety. However, some studies did not find any significant association between parity and antenatal depression/ anxiety $(31,32)$. Previous experience of pregnancy may lessen uncertainty and women may feel more confident. Also, being already mother may alter the attribution to the current pregnancy and diminish the psychological burden of women.

There are other sociodemographic factors which may be related to antenatal depression and anxiety. Housing status is associated with antenatal depression and anxiety (7). However, in this study, it was not linked to antenatal depression and anxiety. Ali et al. reported that the number of people at home was not related to anxiety and depression (6). Similar results were obtained in this study.

Smoking was found correlated with antenatal depression in patients with threatened preterm labor (22). Anxiety in early pregnancy is also related to smoking prior to pregnancy (28). Abstaining from smoking during pregnancy has not decreased the risk of antenatal depression (33). However, it is not clear that smoking increases the risk of depression or it is a result of depression which is associated with unhealthy behavior (4). Present study failed to demonstrate any association between smoking and depression or anxiety.

Zhu et al. reported that threatened miscarriage is associated with depression and anxiety in early pregnancy (12). In the present study, although the vaginal bleeding group had significantly higher anxiety levels, vaginal bleeding was not related to depression or anxiety. Lupattelli et al. reported that women with depression presented a significant moderate increased risk of vaginal bleeding in early pregnancy and mid pregnancy (34). Collaboration of glucocorticoids, progesterone, prolactin and the immune system is required for favorable pregnancy outcomes (35). Patients experiencing depression and anxiety have neuroendocrine disturbances as in the hypothalamic-pituitary-adrenocortical (HPA) axis (24). These neuroendocrine disturbances may disarrange the delicate hormonal and immune harmony of pregnancy and result in vaginal bleeding. This study found no relationship between depression/anxiety and vaginal bleeding. Due to cross-sectional design of the present study, it is not possible to reach an implication of whether depression/anxiety is a risk factor for vaginal bleeding in early pregnancy. To explore this causal link, prospective longitudinally designed studies are necessary.

In the present study, patients with psychiatric history were excluded. This gave the opportunity to investigate the relation between threatened abortion and anxiety/depression independent from past psychiatric history and psychotropic drugs. There are several limitations to the study. Our results were based on self-report measures; we did not use clinically structured interviews. However, Grant et al. reported that assessments by either a clinical interview or maternal self-report can predict postnatal anxiety and mood disorders (36). Because of study design, it was not possible to reach a conclusion regarding casualty. Further studies with longitudinal design will provide data about the etiology of antenatal depression and anxiety.

\section{Conclusion}

Both prenatal depression and anxiety are among the biggest predictors of postpartum depression (37). Antenatal care visits provide critically important opportunities for mental health interventions to occur (5). This study showed that pregnant women with or without threatened abortion were similarly affected by anxiety or depression. Therefore, clinicians should pay attention to the mental health status of all pregnant women equally

Acknowledgment: We thank to all our patients participated to our study. Also, we thank to our nurse Pakize Kahveci for her help.

Funding: There is no funding or financial support used for this study.

Declaration of interest: The authors report no conflicts of interest. 
Author contribution: BS: Astepe had the study conception, designed the study, performed statistical analyses and interpretation of data; had literature searches, participated in drafting of the manuscript and critical revisions. SB: performed statistical analyses and interpretation of data, had literature searches;participated in drafting of the manuscript and critical revisions.

\section{References}

1. Sağduyu A, Ögel K, Özmen E, Boratav C. Depression in primary health care. Turk Psikiyatri Derg. 2000;11:3-6

2. Muzik M, Marcus SM, Heringhausen JE, Flynn H. When depression complicates childbearing: guidelines for screening and treatment during antenatal and postpartum obstetric care. Obstet Gynecol Clin North Am. 2009; 36(4):771-88.

3. Çalık YK, Aktaş S. Depression in pregnancy: prevalance, risk factors and treatment. Psikiyatride Güncel Yaklaşımlar-Current Approaches in Psychiatry. 2011;3 (1):142-62.

4. Biaggi A, Conroy S, Pawlby S, Pariante CM. Identifying the women at risk of antenatal anxiety and depression: a systematic review. J Affect Disord. 2016;191:62-77.

5. Gelaye B, Rondon M, Araya R, Williams MA. Epidemiology of maternal depression, risk factors, and child outcomes in low-income and middle-income countries. Lancet Psychiatry. 2016;3(10):973-82.

6. Ali NS, Azam IS, Ali BS, Tabbusum G, Moin SS. Frequency and associated factors for anxiety and depression in pregnant women: a hospital-based cross-sectional study. ScientificWorldJournal. 2012;2012:653098.

7. Karmaliani R, Asad N, Bann CM, Moss N, Mcclure EM, Pasha $\mathrm{O}$, et al. Prevalence of anxiety, depression and associated factors among pregnant women of Hyderabad, Pakistan. Int J Soc Psychiatry. 2009;55(5):414-24.

8. Weiss JL, Malone FD, Vidaver J, Ball RH, Nyberg DA, Comstock $\mathrm{CH}$, et al. Threatened abortion: a risk for poor pregnancy outcome, a population-based screening study. Am J Obs Gynecol. 2004;190(3):745-50.

9. Snell BJ. Assesment and management of bleeding in the first trimester of pregnancy. J Midwifery Womens Heal. 2009;54(6):483-91.

10. Blackmore ER, Côté-Arsenault D, Tang W, Glover V, Evans J, Golding J, et al. Previous prenatal loss as a predictor of perinatal depression and anxiety. Br J Psychiatry. 2011;198(5):373-8.

11. Chojenta C, Harris S, Reilly N, Forder P, Austin MP, Loxton D. History of pregnancy loss increases the risk of mental health problems in subsequent pregnancies but not in the postpartum. PLoS One. 2014;9(4):e95038.

12. Zhu CS, Tan TC, Chen HY, Malhotra R, Allen JC, Østbye $\mathrm{T}$. Threatened miscarriage and depressive and anxiety symptoms among women and partners in early pregnancy.
J Affect Disord. 2018;237:1-9.

13. Abiodun OA. A validity study of the Hospital Anxiety and Depression Scale in general hospital units and a community sample in Nigeria. Br J Psychiatry. 1994;165(5): 669-72.

14. Zigmond AS, Snaith RS. The hospital anxiety and depression scale. Acta Psychiatr Scand. 1983;67(6):361-70.

15. Bjelland I, Dahl AA, Haug TT, Neckelmann D. The validity of the Hospital Anxiety and Depression Scale. An updated literature review. J Psychosom Res. 2002;52(2): 69-77.

16. Herrmann C. International experiences with the Hospital Anxiety and Depression Scale--a review of validation data and clinical results. J Psychosom Res. 1997;42(1):17-41.

17. Lee AM, Lam SK, Sze Mun Lau SM, Chong CS, Chui HW, Fong DY. Prevalence, course, and risk factors for antenatal anxiety and depression. Obstet Gynecol. 2007; 110(5):1102-12.

18. Chan CY, Lee AM, Lam SK, Lee CP, Leung KY, Koh YW, et al. Antenatal anxiety in the first trimester: risk factors and effects on anxiety and depression in the third trimester and 6-week postpartum. OJ Psych. 2013;3:301-10.

19. Aydemir Ö, Güvenir T, Küey L. Validity and reliability of Turkish version of Hospital Anxiety and Depression Scale. Turkish Journal of Psychiatry 1997;8(4):280-7.

20. Golbasi Z, Kelleci M, Kisacik G, Cetin A. Prevalence and correlates of depression in pregnancy among Turkish women. Matern Child Health J. 2010;14(4):485-91.

21. Yanikkerem E, Ay S, Mutlu S, Goker A. Antenatal depression: prevalence and risk factors in a hospital based Turkish sample. J Pak Med Assoc. 2013;63(4):472-7.

22. Dagklis T, Tsakiridis I, Chouliara F, Mamopoulos A, Rousso D, Athanasiadis A, et al. Antenatal depression among women hospitalized due to threatened preterm labor in a high-risk pregnancy unit in Greece. J Matern Neonatal Med. 2018;31(7):919-25.

23. Zhao Y, Kane I, Mao L, Shi S, Wang J, Lin Q, et al. The prevalence of antenatal depression and its related factors in Chinese pregnant women who present with obstetrical complications. Arch Psychiatr Nurs. 2016;30(3):316-21.

24. Bödecs T, Szilágyi E, Cholnoky P, Sándor J, Gonda X, Rihmer Z, et al. Prevalence and psychosocial background of anxiety and depression emerging during the first trimester of pregnancy: data from a Hungarian populationbased sample. Psychiatr Danub. 2013;25(4):352-8.

25. Qiao YX, Wang J, Li J, Ablat A. The prevalence and related risk factors of anxiety and depression symptoms among Chinese pregnant women in Shanghai. Aust N Z J Obstet Gynaecol. 2009;49(2):185-90.

26. Balestrieri M, Isola M, Bisoffi G, Calo S, Conforti A, Driul L, et al. Determinants of antepartum depression: a multicenter study. Soc Psychiatry Psychiatr Epidemiol. 
2012;47(12):1959-65..

27. Richardson A, Raine-Fenning N, Deb S, Campbell B, Vedhara K. Anxiety associated with diagnostic uncertainty in early pregnancy. Ultrasound Obstet Gynecol. 2017; $50(2): 247-54$

28. Rubertsson C, Hellström J, Cross M, Sydsjö G. Anxiety in early pregnancy: prevalence and contributing factors. Arch Womens Ment Health. 2014;17(3):221-8.

29. Shapiro GD, Séguin JR, Muckle G, Monnier P, Fraser W. Previous pregnancy outcomes and subsequent pregnancy anxiety in a Quebec prospective cohort. J Psychosom Obstet Gynaecol. 2017;38(2):121-32.

30. Bicking Kinsey C, Baptiste-Roberts K, Zhu J, Kjerulff $\mathrm{KH}$. Effect of previous miscarriage on the maternal birth experience in the First Baby Study. J Obstet Gynecol Neonatal Nurs. 2013;42(4):442-50.

31. Fisher J, Tran T, La BT, Kriitmaa K, Rosenthal D, Tran T. Common perinatal mental disorders in northern Viet Nam: community prevalence and health care use. Bull World Health Organ. 2010;88(10):737-45.

32. Faisal-Cury A, Rossi Menezes P. Prevalence of anxiety and depression during pregnancy in a private setting sample. Arch Womens Ment Health. 2007;10(1):25-32.

33. Jeong HG, Lim JS, Lee MS, Kim SH, Jung IK, Joe SH. The association of psychosocial factors and obstetric history with depression in pregnant women: focus on the role of emotional support. Gen Hosp Psychiatry. 2013;35(4): 354-8.

34. Lupattelli A, Spigset O, Koren G, Nordeng H. Risk of vaginal bleeding and postpartum hemorrhage after use of antidepressants in pregnancy: a study from the Norwegian Mother and Child Cohort Study. J Clin Psychopharmacol. 2014;34(1):143-8.

35. Parker VJ, Douglas AJ. Stress in early pregnancy: maternal neuro-endocrine-immune responses and effects. J Reprod Immunol. 2010;85(1):86-92.

36. Grant KA, McMahon C, Austin MP. Maternal anxiety during the transition to parenthood: a prospective study. J Affect Disord. 2008;108(1-2):101-11.

37. Robertson E, Grace S, Wallington T, Stewart DE. Antenatal risk factors for postpartum depression: a synthesis of recent literature. Gen Hosp Psychiatry. 2004;26 (4):289-95 